\title{
Interesting image of Brain CT angiogram
}

CONTRIBUTOR:

Karthikeyan $\mathrm{K} \mathrm{V}^{*}$

*Senior Consultant \& Associate Professor, Department of Neurosurgery, Chettinad Super Speciality Hospital, Chettinad Academy of Research and Education, Chennai, India.

Chettinad Health City Medical Journal 2020; 9(1): 66

DOI: https://doi.org/10.36503/chcmj9(1)-12

30 year old man presented with headache and seizure evaluated with MRI brain and then CT angiogram of brain.

The CT angiogram showed a giant (more than $6 \mathrm{~cm}$ ) sized bag of vessels in the right perisylvian area which were supplied by both Anterior cerebral artery and Middle cerebral artery. The venous drainage is to both superficial and deep venous system. The diagnosis is Complex Spetzler Martin Grade IV AV malformation of brain.

The management of these kind of AVMs is complex and requires combined Embolization and surgical excision of the AVM.

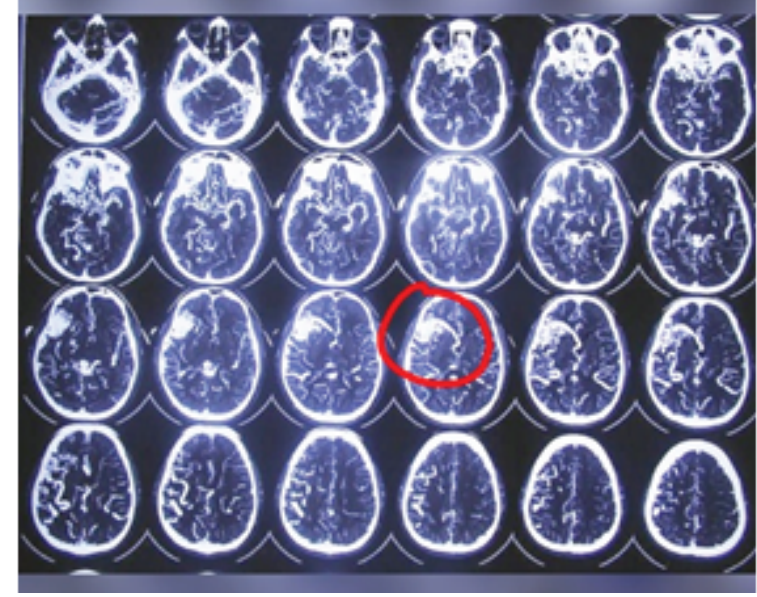

CT angio showing Giant AVM in right perisylvian region shown in red circle. 